\title{
Genotyping of Echinococcusgranulosus Isolates from Human, Sheep and Cattles Hydatid Cysts in Some Central Euphrates Provinces, Iraq
}

\author{
Zahraa Mohammed Salih Mahdi ${ }^{1}$, Ahmed Khudhair Al-Hamairy ${ }^{2}$, Hadi Mezeil Al-Rubaiey ${ }^{2}$ \\ ${ }^{I}$ M.Sc. Student, ${ }^{2}$ Prof. Dr., College of Science for Women, University of Babylon, Biology Dept. Hilla, Iraq
}

\begin{abstract}
A molecular study was conducted for the period from August 2018 till March 2019. This study included the collection of 60 samples of human and animal hydatid cysts (sheep and Cattles), human samples collected from Al-Diwaniyah hospital. Whereas the animal samples were collected from Al- Najaf and Al-Diwaniyah provinces abattoirs .DNA was extracted from the germinal layer of cysts (for humans, sheep and cows) as well as from the protoscolices of fertile cystic fluid. The PCR series reaction technique was performed using touch down for the multiplication of the Cox 1 gene. Molecular examination showed that DNA extracted from protoscolices was better than DNA extracted from the germinal layer when PCR genes were amplified. The gene sequencer method and the phylogenetic tree analysis were conducted for nine PCR samples consisting of three samples for everyone humans, cows and sheep. The results showed that there are three strains in Iraq: sheep strain (G1), cattle strain (G3) and camel strain (G6). The current study reveals the cattle strain (G3) It was the most present and distributed by $66.6 \%$ and this proves that they are most closely related associated with human, sheep and cattle infections.
\end{abstract}

Keywords: Echinococcusgranulosus, Genotyping, Human.

\section{Introduction}

Hydatid disease, known as hydatidosis or Echinococcosis, is a common human-zoonotic disease that arises as a result of the eggs of Echinococcusgranulosus in feces of dogs (as final hosts) and delivered to the external environment where contaminated of water, vegetables, fruits, etc., it's endemic disease in all continents of the world except in Antarctica ${ }^{1}$ and ${ }^{2}$.Hydatid cysts have been known since ancient times, and are considered serious epidemic diseases that are harmful to human health and economically ${ }^{3}$ and ${ }^{4}$. According to the World Health Organization (WHO), the disease causes 19,300

\section{Corresponding Author:}

\section{Ahmed Khudhair Al-Hamairy}

Prof. Dr., College of Science for Women, University of Babylon, Biology Dept. Hilla, Iraq

e-mail: ahmedalhamiary@gmail.com deaths globally each year, more than one million people affected by the disease and livestock losses. ${ }^{5}$ and ${ }^{4}$. The disease is prevalent in livestock husbandry areas and carnivores in close contact with humans that help to complete the life cycle of the parasite causing the disease ${ }^{6}$ . The parasite needs two hosts to complete its life cycle. The first host includes carnivores and represents the definitive host, the second host includes the herbivores and represents the intermediate host, the human is an accidental intermediate host does not contribute to the perpetuation of the life cycle of the parasite and infected in several ways, including food and drink contaminated with parasite eggs or direct contact with infected $\operatorname{dog} \mathrm{s}^{7}$. The disease infected and affects many organs in the human body and the others intermediate host and the most vulnerable organs are liver and lung followed by spleen, kidney, heart, brain, spinal cord, urethra, uterus, fallopian tube, pancreas, mesenteric membrane, muscles and other organs, and brain infection is more common in children ${ }^{8}$. In Iraq, cystic echinococcosisis one of the 
main health concerns ${ }^{9}$.It is an endemic disease and a major health problem in the country where it is known as Iraqi cancer ${ }^{10}$. Molecular detection techniques is a modern and sensitive method used to determine the type and strain of the E. granulosusparasite ${ }^{11}$. Molecular studies indicated that there are 10 distinct genotypes of the parasite ${ }^{12}$. Genotypes or strains were termed G (G1), based on the analysis of the sequence of mitochondrial cytochrome Coxl genes. The E.granulosus strains were divided into several groups based on the sequence of mitochondrial genes, including the sheep strains $E$. granulosussensustricto, which includes genotypes (G1G3), horse strains Echinococcusequinus (G4), the Camel strains Echinococcuscanadensis (G6) and the pig strains G7 (G10-G6) and the elk strain G9 (G8 and G10), and the elk strain G9 is currently classified as G7 ${ }^{13}$.

\section{Materials and Method}

Samples Collection and Preparation of Hydatid Cysts: The present study included collection of 60 samples of human and animal hydatid cysts (sheep and cows), human samples collected from Al-Diwaniyah hospital. Whereas the animal samples were collected from Al- Najaf and Al-Diwaniya provinces abattoirs ..from August 2018 till March 2019. The hydatid cysts were isolated from slaughtered cattle and sheep and placed in an ice-cooled container and transferred to the Advanced Parasitology Laboratory at the College of Science for Women/University of Babylon, the samples had been washed directly with water to remove dirt and blood on them. Firstly the surface of the hydatid cyst is sterilized with $70 \%$ ethanol. Sterile medical syringes of $10 \mathrm{ml}$ were used to remove the cyst fluid and the collection of protoscolices were performed under sterile conditions.

The cyst fluid was withdrawn with the protoscolices and placed in a beaker $250 \mathrm{ml}$. Germinal layer was extracted and placed in a sterile petridish containing a physiological saline solution $(0.9 \%)$ and then washed with a washing bottle containing saline phosphate buffer solution (PBS) and several times to extract the largest number of protoscolices, and later collected in sterile test tubes and centrifuged three times Speed of $3000 \mathrm{rev} /$ min for 15 minutes each time. $70 \%$ ethyl alcohol was added to these tubes for preservation with pieces of the germinal layer and subsequently used in polymerase chain reaction (PCR) and genetic sequencing to detect dominant parasite strains.
PCR Technique: PCR techniquewas performed for in detection and genotyping of Echinococcusgranulosus hydatid cyst based on mitochondrial Cox1 gene in isolates. This technique was carried out according to method described by [14] as following steps:

Genomic DNA Extraction: Genomic DNA from hydatid cyst fluid samples were extracted by using gSYAN DNA Extraction KitGeneaid.

Genomic DNA Examination: The extracted blood genomic DNA was checked by using Nanodrop spectrophotometer (THERMO. USA), which measured DNA concentration $(\mathrm{ng} / \mu \mathrm{L})$ and check the DNA purity by reading the absorbance at $(260 / 280 \mathrm{~nm})$ as following steps:

1. After opening up the Nanodrop software, chosen the appropriate application (Nucleic acid, DNA).

2. A dry wipe was taken and cleaned the measurement pedestals several times. Then carefully pipette $2 \mu \mathrm{l}$ of free nuclease water onto the surface of the lower measurement pedestals for blank the system.

3. The sampling arm was lowered and clicking OK to initialized the Nanodrop, then cleaning off the pedestals and $1 \mu 1$ of blood genomic DNA was added to measurement. PCR master mixwas prepared by using (Maxime PCR PreMix Kit) and this master mix done according to company instructions. After that, these PCR master mix component that mentioned in table above placed in standard PCR PreMix Kit that containing all other components which needed to PCR reaction such as (Taq DNA polymerase, dNTPs, Tris- $\mathrm{HCl} \mathrm{pH}$ : 9.0, $\mathrm{KCl}$, $\mathrm{MgCl}_{2}$, stabilizer, and tracking dye). Then, all the PCR tubes transferred into Exispin vortex centrifuge at 3000rpm for three minutes. Then placed in PCR Thermocycler (BioRad.USA).

PCR Product Analysis: The PCR products of mitochondrial genes were analyzed by agarose gel electrophoresis following steps:

1. $1 \%$ Agarose gel was prepared in using $1 \mathrm{X}$ TBE and dissolving in water bath at $100{ }^{\circ} \mathrm{C}$ for 15 minutes, after that, left to $\operatorname{cool} 50^{\circ} \mathrm{C}$.

2. Then $3 \mu 1$ of ethidium bromide stain were added into agarose gel solution.

3. Agarose gel solution was poured in tray after fixed the comb in proper position after that, left to 
solidified for 15 minutes at room temperature, then the comb was removed gently from the tray and $10 \mu 1$ of PCR product were added in to each comb well and $5 \mathrm{ul}$ of (100bp Ladder) in one well.

4. The gel tray was fixed in electrophoresis chamber and fill by $1 \mathrm{X}$ TBE buffer. Then electric current was performed at 100 volt and $80 \mathrm{AM}$ for 1 hour.

5. PCR products (450bp) cox 1 gene was visualized by using UV ttransilluminator.

DNA Sequencer Method: The process of DNA sequencing to identify strains of some positive E.granulosus isolates is carried out according to the following steps:

1. The PCR product of the cox1 genes was sent to Macrogenin South Korea in refrigerated container by DHL courier for DNA sequencing by AB DNA sequencing system.

2. DNA sequence analysis (Phylogenetic tree analysis) using molecular genetic analysis, and Mega 6.0 software programmed and sequential alignment analysis based on convergence analysis.
Evolutionary distances were calculated using the maximum probability method and utilizing the UPGMA tool tree method.

3. Analysis of strains identification by analysis of genetic trees between local E.granulosus isolates and known E.granulosus isolates at NCBI-Blast

4. Finally, the E.granulosus isolates identified in NCBI-GenBank were provided for the GenBank registration number.

\section{Results and Discussion}

Results of the Polymerase Chain Reaction Technique for Cox1 Gene: The results of PCR technique showed the success of all amplification of extracted DNA from the protoscolices and the germinal layer of $\operatorname{Cox}(1)$ mitochondrial gene whereas the results were positive for all samples of human cysts $(1,2$ and $3)$ and sheep (4, 5 and 6$)$ and cows (7, 8 and 9) after conducting the gel agarose electrophoresis, which showed the presence of the diagnostic gene of the mitochondria Cox (1) of E.granulosus at a molecular weight of $450 \mathrm{bp}$ as in Figure (4-1) and this is consistent with many studies such as [15] and [16].

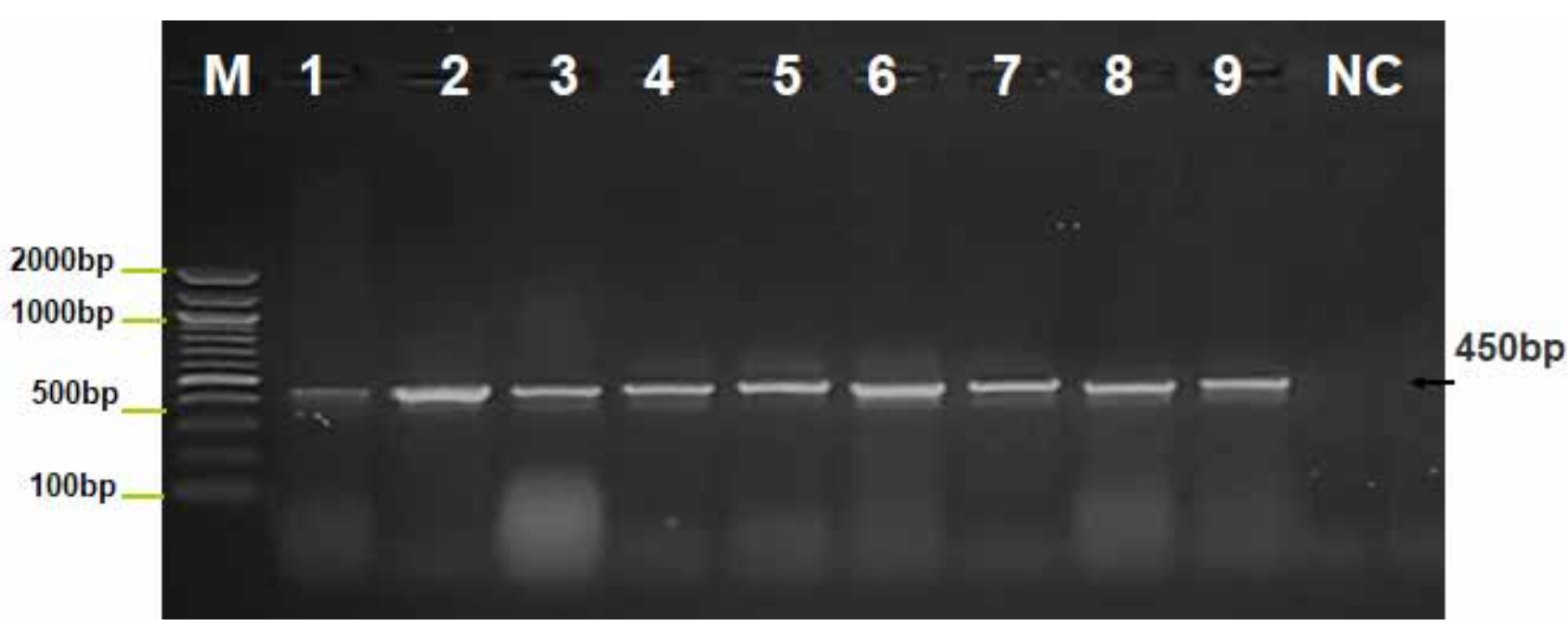

Figure 1: Agarose gel electrophoresis image that showed the PCR product analysis of mitochondrial cytochrome (COX1) gene in Echinococcusgranulosus hydatid cysts isolated from Human, Sheep and Cattle..

Where M: marker (2000-100bp), lane (1-3) Human hydatid cysts isolates, lane (4-6) Sheep hydatid cysts isolates, and lane (1-3) cattle hydatid cysts isolates, positive cox1 gene at (450bp) PCR product size. NC : non templet negative control. 
Results of DNA Sequencing Technique and Genetic Tree Analysis

Result of E. granulosus Genotype: Three random samples were selected for humans, sheep and cows because of the high physical cost of DNA sequencing. The selected samples were sent to Macrogen company in South Korea for the purpose of determining the DNA sequence of the cox1 mitochondrial gene, which was used to determine the position of E.granulosus . The phylogenetic tree was written using the evolution distance, which was measured using the Composite Likelihood Maximum method (UPGMA tree) in MEGA 6.0 version.

Human: The results of the DNA sequence of human cysts indicate that sheep (G1) and buffalo (G3) may be responsible for human infections in Al-Najaf and Al-Diwaniyah governorates, where the strain (G1) was found in $33.33 \%$ of samples and identical rates $96 \%$. With the comparable sample in the genebank under the symbol KP161207.1 from Africa, and the cattle strain (G3) in $66.66 \%$ of the samples with an identical rates ranging from $99 \%$ to $100 \%$ when comparable sample in the genebank with accession number M84663.1 The isolates were recorded in GenBank with the following accession number: MN514880, MN514881 and MN514882

Sheep: The results of the PCR phylogenetic analysis of three samples of hydatid cysts of infected sheep indicate that sheep strain (G1) with a percentage of $96 \%$ with the standard sample compared to them in the genebank, accession number M84663.1 from Turkey, and the cattle (G3) with identical rate $99 \%$ the standard specimen comparing them in the genebank with accession number KP161207.1 from Africa and the camel strain (G6) with identical rate $100 \%$, the comparable specimens that were compared in the genebank with accession number JF964263 from Iran is responsible for infection in the isolates samples in the present study in genebank were recorded in accession number MN514883, MN514884 and MN514885

Cattle: The results of PCR phylogenetic analysis of three samples of hydatid cysts of infected cows, indicate that cattle (G3) strain may be responsible for cattle infections in Al- Najaf and Al-Diwaniyah governorates with a prevalence rates $(100 \%)$ and identical rates $(100 \%)$ and $(99 \%)$ with the comparable sample. That have accession number in NCBI is M84663.1for Turkey strains in the gene bank. The results of PCR phylogenetic analysis of three samples of hydatid cysts of infected cows, indicate that cattle (G3) strain may be responsible for cattle infections in Al- Najaf and AlDiwaniyah governorates with a prevalence rates $(100 \%)$ and identical rates $(100 \%)$ and $(99 \%)$ conformity with the comparable standard sample. That have accession number in the genebank under the code M8466.1 from Turkey, isolates samples in the present study were recorded in GenBank with the following numbers MN514886, MN514887, and MN514888, as shown in Table (1) and (2).

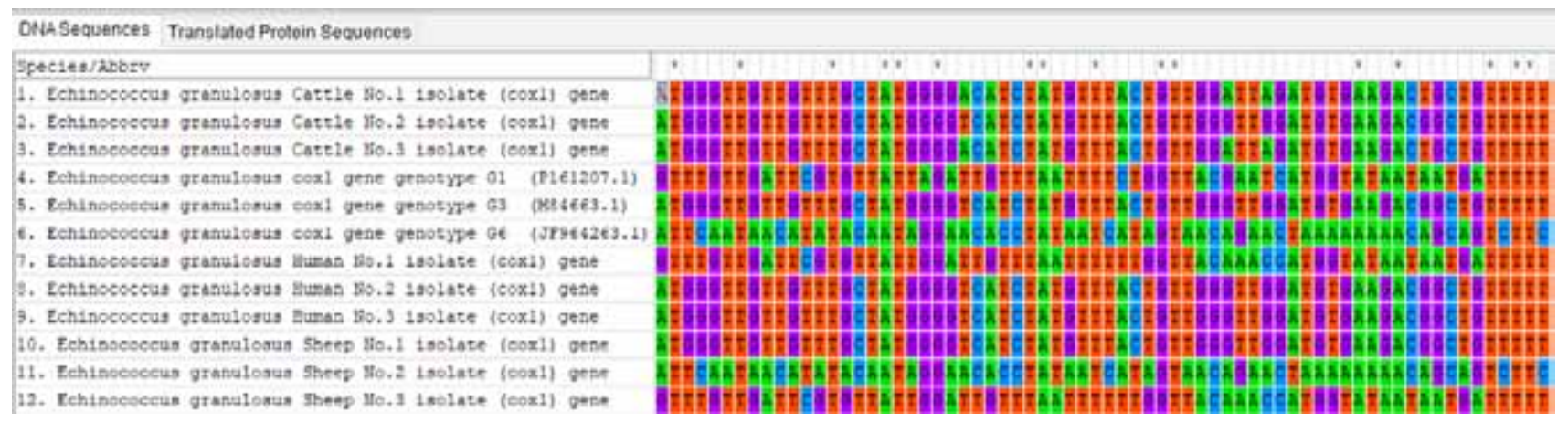

Figure 2: Multiple sequence alignment analysis of mitochondiral Cox1 gene partial sequence in local Echinococcusgranulosus Human, Sheep, and cattle

Relation of the Current Study Strains to Some Other Strains in Iraq and Nearby Countries: The genetic tree of human, sheep and cattle isolates was written using the development distance, which was measured using the Maximum Composite Likehoodmethod (UPGMA tree) in programmed software (Version 6.0 MEGA). Human, sheep and cattle isolates were compared with some other isolates 
recorded in NCBI-BLAST. The isolates of humans (1) and sheep (3) showed the closest similarity to the isolates of African E.granulosus belonging to the strain (G1) numbered KP161207.1) recorded in NCBI-BLAST, and showed the isolates of humans $(3,2)$ and sheep (1) and cattle $(1,2,3)$. The closest similarity in the isolates of the
Turkish E.granulosus belonging to the cattle strain (G3) numbered M84663.1), and the isolation of sheep (2) showed the closest similarity to the isolates of Iranian $E$. granulosus belonging to the camels strain (G6 numbered Jf964263) recorded in NCBI-BLAST.
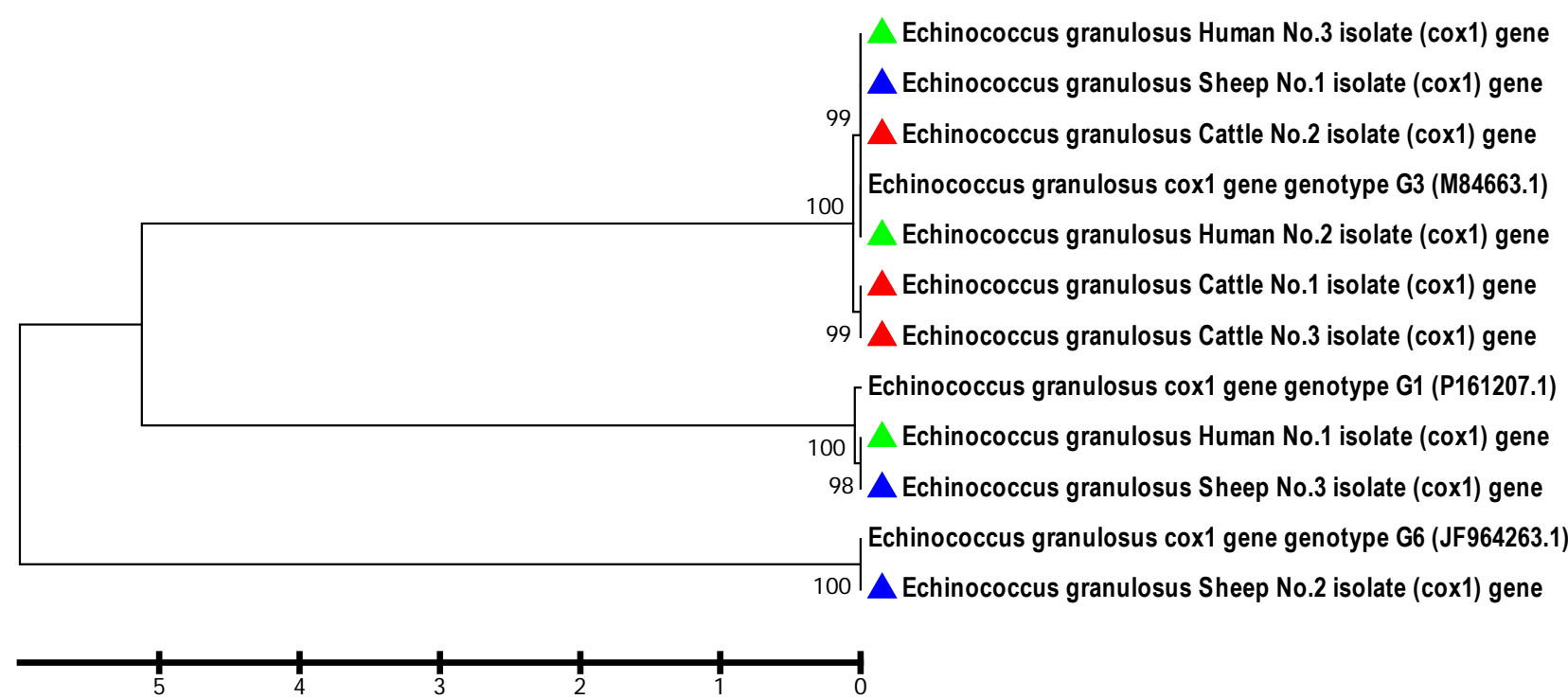

Figure 3: Phylogenetic tree analysis based on the mitochondiral Cox1 gene partial sequence that used for Echinococcusgranulosus typing detection.

Table 2: NCBI -BLAST Homology sequence identity between local Echinococcusgranulosus Human, Sheep, and cattle isolates with NCBI-BLAST Echinococcusgranulosus related Genotypes isolates.

\begin{tabular}{|c|c|c|c|c|c|c|}
\hline \multirow[b]{2}{*}{ Local isolate } & \multirow{2}{*}{$\begin{array}{l}\text { Gene bank submission } \\
\text { accession number }\end{array}$} & \multicolumn{5}{|c|}{ NCBI-BLAST Homology Sequence identity } \\
\hline & & NCBI BLAST identity isolate & Genotype & $\begin{array}{l}\text { Accession } \\
\text { Number }\end{array}$ & Country & $\begin{array}{l}\text { Identity } \\
(100 \%)\end{array}$ \\
\hline $\begin{array}{l}\text { local E.granulosus } \\
\text { Human isolate No.1 }\end{array}$ & $\begin{array}{l}\text { Banklt2266832 Seq1 } \\
\text { MN514880 }\end{array}$ & Echinococcusgranulosus & Genotype 1 & KP161207.1 & Africa & $96 \%$ \\
\hline $\begin{array}{l}\text { local E.granulosus } \\
\text { Human isolate No. } 2\end{array}$ & $\begin{array}{l}\text { Banklt2266832 Seq2 } \\
\text { MN514881 }\end{array}$ & Echinococcusgranulosus & Genotype 3 & M84663.1 & Turkey & $100 \%$ \\
\hline $\begin{array}{l}\text { local E.granulosus } \\
\text { Human isolate No.3 }\end{array}$ & $\begin{array}{l}\text { Banklt2266832 Seq3 } \\
\text { MN514882 }\end{array}$ & Echinococcusgranulosus & Genotype 3 & M84663.1 & Turkey & $99 \%$ \\
\hline $\begin{array}{l}\text { local E.granulosus } \\
\text { Sheep isolate No.1 }\end{array}$ & $\begin{array}{l}\text { Banklt2266832 Seq } 4 \\
\text { MN514883 }\end{array}$ & Echinococcusgranulosus & Genotype 3 & M84663.1 & Turkey & $99 \%$ \\
\hline $\begin{array}{l}\text { local E.granulosus } \\
\text { Sheep isolate No. } 2\end{array}$ & $\begin{array}{l}\text { Banklt2266832 Seq5 } \\
\text { MN514884 }\end{array}$ & Echinococcusgranulosus & Genotype 6 & JF964263 & Iran & $100 \%$ \\
\hline $\begin{array}{l}\text { local E.granulosus } \\
\text { Sheep isolate No.3 }\end{array}$ & $\begin{array}{l}\text { Banklt2266832 Seq6 } \\
\text { MN514885 }\end{array}$ & Echinococcusgranulosus & Genotype 1 & KP161207.1 & Africa & $96 \%$ \\
\hline $\begin{array}{l}\text { local E.granulosus } \\
\text { Cattle isolate No.1 }\end{array}$ & $\begin{array}{l}\text { Banklt2266832 Seq7 } \\
\text { MN514886 }\end{array}$ & Echinococcusgranulosus & Genotype 3 & M84663.1 & Turkey & $99 \%$ \\
\hline $\begin{array}{l}\text { local E.granulosus } \\
\text { Cattle isolate No. } 2\end{array}$ & $\begin{array}{l}\text { Banklt2266832 Seq8 } \\
\text { MN514887 }\end{array}$ & Echinococcusgranulosus & Genotype 3 & M84663.1 & Turkey & $100 \%$ \\
\hline $\begin{array}{l}\text { local E.granulosus } \\
\text { Cattle isolate No. } 3\end{array}$ & $\begin{array}{l}\text { Banklt2266832 Seq9 } \\
\text { MN514888 }\end{array}$ & Echinococcusgranulosus & Genotype 3 & M84663.1 & Turkey & $99 \%$ \\
\hline
\end{tabular}


Table 2: Distribution and frequency of genotypes detected in the present study and their percentages from NCBI information.

\begin{tabular}{|l|c|c|c|c|c|c|c|}
\hline Samples Type & $\begin{array}{c}\text { Genotype 1 } \\
\text { (G1) }\end{array}$ & $\mathbf{( \% )}$ & $\begin{array}{c}\text { Genotype 3 } \\
(\mathbf{G 3 )}\end{array}$ & $\mathbf{( \% )}$ & $\begin{array}{c}\text { Genotype 6 } \\
\text { (G6) }\end{array}$ & (\%) & Total \\
\hline Human & 1 & 11.1 & 2 & 22.2 & 0 & 0 & 3 \\
\hline Sheep & 1 & 11.1 & 1 & 11.1 & 1 & 11.1 & 3 \\
\hline Cows & 0 & 0 & 3 & 33.3 & 0 & 0 & 3 \\
\hline Total & 2 & 22.2 & 6 & 66.6 & 1 & 11.1 & 9 \\
\hline
\end{tabular}

Financial Disclosure: There is no financial disclosure.

Conflict of Interest: None to declare.

Ethical Clearance: All experimental protocols were approved under the College of Science for Women, Iraq and all experiments were carried out in accordance with approved guidelines.

\section{References}

1. Paniker CJ, Ghosh, S. Paniker's textbook of medical parasitology.7 thEdn., Jaypee Brothers Medical Publishers (P) Ltd. New Delhi.2013: 127134.

2. Otero-Abad B, Torgerson PR. A systematic review of the epidemiology of echinococcosis in domestic and wild animals. PLoS neglected tropical diseases.2013; 7(6): e2249

3. Thompson R. Biology and systematics of Echinococcus. In Advances inparasitology. Academic Press. 2017; 95 : 65-109 pp.

4. Bogitsh B, Carter C, Oeltmann T. Human Parasitology 5Ed,. General characteristics of thecestoidea., Academic Press.2019: 243-25

5. Higuita N, Brunetti E, McCloskey C. Cystic echinococcosis. Journal ofclinical microbiology. 2016; 54(3): 518523.

6. Hayajneh, F.M.F.; Althomali A. Prevalence and characterization Hydatidosis in animals slaughtered at Al Taif abattoir, Kingdom of Saudi Arabia. Open Journal of Animal Sciences. 2014; 4(01): 38-41.

7. Romig T, Deplazes P. Ecology and life cycle patterns of Echinococcusspecies. In Advances in parasitology. Academic Press.2017; 95,: 213-314

8. Khurana, M. Ruptured Hydatid cyst of lung.urrent Pediatric Research. Scintific Publishers of India. 2012; 16(2):156-158.
9. Cox F. Modern Parasitology: A textbook of

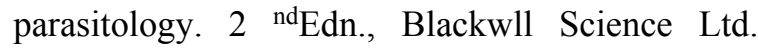
Oxford.2004: 30252.

10. Abdulhameed M. A retrospective studyof human cystic echinococcosisin Basrah province, Iraq. Actatropica.2019; 178: 130-133.

11. SalihN.DNA Analysis of Echinococcus of Human and Sheep Origin in NinevahProvince, Iraq by PCRRAPD Technique, J. Rivista di Parassitol.2001; 17(3):221-232.

12. Nakao M. A molecular phylogeny ofthe genus Echinococcus inferred from complete mitochondrial genomes. Parasitology.2006; 134: 713-722.

13. Rojas C. Echinococcusgranulosussensulato genotypes infecting humans-review of current knowledge. International Journal for Parasitology.2014; 44(1): 9-18.

14. Nikmanesh B, Mirhendi H. Genotyping of EchinococcusgranulosusIsolates from Human Clinical Samples Based on Sequencing of Mitochondrial Genes in Iran, Tehran. Iranian J. Parasitol.2014; 9(1): 20-27.

15. Ahmed B, Mero W, Salih A. Molecular Characterization of Echinococcusgranulosus Isolated from Human Hydatid Cyst Using Mitochondrial Cox1 Gene Sequencing in Dohuk Province-Kurdistan Region, Iraq.Science Journal of University of Zakho. 2013; 1(1): 72-80.

16. Ali M, Rahi A. A First DNA sequencing of hydatid agent isolated from human in Iraq. Journal of Pure and Applied Microbiology.2016; 10(2): 1015-1020

17. Agha A.Genotyping of Cystic Echinococcosis Isolates fromHuman and Animals Clinical Samples. M.Sc. thesis, Veterinary Medicine College. Universityof Al-Qadisiyah. Iraq.2015: 48-87 